\title{
Integrity: doing the right thing for the right reason (/review/10.5860/CHOICE.45-4080)
}

Killinger, Barbara. (/search?exactauthor=Killinger, Barbara) McGill-Queen's, 2007 204p, $9780773532878 \$ 27.95$

LC Call Number: BJ (/search?lcstart=BJ)1533

Killinger (a clinical psychologist and author of Workaholics: The Respectable Addicts, 1992) uses the concept of integrity as an umbrella to cover a wide range of personal qualities for living a moral, ethical, and spiritual existence. She divides the book into three sections. In part 1 the author defines integrity and relates the concept to traits such as honesty, sympathy, conscience, empathy, compassion, fairness, self-control, and duty. In part 2 she argues that integrity has been lost in much of contemporary culture and offers reasons why this is so. In part 3 she offers a series of lists that detail ways that people can improve the level of integrity in their own lives and in the lives of those around them. Killinger brings a Jungian approach to aspects of her discussion. The book moves across so much psychological ground that it sometimes reads like a textbook listing of terms and concepts from positive psychology. However, the book certainly provides a broad-ranging, comprehensive exploration of the concept of integrity and a detailed how-to guide for achieving it in one's life.

Summing Up: Recommended. Lower- and upper-division undergraduates, professionals, and general readers.

Reviewer: R. Levine (/search?reviewer=R. Levine), California State University--Fresno Recommendation: Recommended

Readership Level: General Readers, Lower-division Undergraduates, Upper-division Undergraduates, Professionals/Practitioners

Interdisciplinary Subjects:

Subject: Social \& Behavioral Sciences - Psychology (/search?q=\&sbj[]=psy)

Choice Issue: mar 2008 vol. 45 no. 7

Choice Review \#: 45-4080

Review DOI: 10.5860/CHOICE.45-4080 